\title{
Feasibility of using fly ash, lime, and bentonite to neutralize acidity
}

\section{of pore fluids}

\author{
I. B. Gratchev ${ }^{1}$, A. Shokouhi ${ }^{2}$, A. Balasubramaniam ${ }^{3}$
}

${ }^{1}$ Lecturer, Griffith School of Engineering, Gold Coast Campus, Griffith University, Parklands Drive, Southport, QLD, 4222, Australia; email: ivangratchev@gmail.com

${ }^{2}$ Griffith School of Engineering, Gold Coast Campus, Griffith University, Parklands Drive, Southport, QLD, 4222, Australia

3 Adjunct Professor, School of Engineering, Gold Coast Campus, Griffith University, Parklands Drive, Southport, QLD, 4222, Australia

\begin{abstract}
Acidic groundwater resulting from the poorly planned use of acid sulfate soils has become a major environmental issue in coastal Australia over the last several years. Use of permeable reactive barriers (PRBs) designed to generate alkalinity by promoting sulfate reduction has recently become popular as an alternative solution to this problem. However, recent studies have also revealed that the long-term performance of such PRBs can be significantly undermined by chemical precipitation and clogging of pore space, which would decrease the buffer capacity and hydraulic conductivity of the reactive material. This study seeks to explore the feasibility of using bentonite in addition to lime and fly ash to form mixtures with a high buffer capacity and permeability that would enable groundwater flow through PRBs over a substantial period of time. A series of laboratory experiments, including buffer capacity and leaching tests, were performed on different mixtures of fly ash with lime and bentonite using acidic fluids of low $\mathrm{pH}$. It was found that the ability of such mixtures to neutralize acidic fluids was mostly controlled by the content of lime. Laboratory data also showed that an addition of bentonite to lime - fly ash mixtures could decrease the buffer
\end{abstract}


capacity of soil. Compaction tests indicated that the presence of bentonite would increase the dry density of mixtures at the optimum moisture content. A series of hydraulic conductivity tests were carried out to study changes in the coefficient of permeability of lime - fly ash mixtures with different contents of bentonite permeated with acidic liquids. The obtained results revealed that the coefficient of permeability of the specimens tended to increase over a period of time, likely due to the changes in the diffuse double layer of bentonite particles.

Keywords: acid fluid, permeable reactive barrier, buffer capacity, fly ash, bentonite

\section{Introduction}

Acid sulfate soils (ASS) that contain iron sulfides (e.g. pyrite) pose a significant environmental, economic and social threat to coastal Australia (White et al. 1997). Although pyrite is relatively chemically inert when undisturbed and submerged under the water table, it can result in the formation of sulphuric acid when exposed to oxygen. The acid will mobilize large amounts of iron (Fe) and aluminium (Al) ions from the soil in the groundwater, and pose an environmental problem that will decrease agriculture and fishery productivity as well as lead to damage steel and concrete infrastructure (Golab et al. 2006). Acidic water can also affect the geotechnical properties of soil including its permeability (Gratchev and Towhata 2010) and strength (Gratchev and Towhata 2013).

Remediation techniques such as one-way floodgates and modified two-way floodgates have been proposed and tested at different sites of coastal lowland in NSW, Australia (Indraratna et al. 2002). A few other methods including pump-and-treat technique and open lime drains have also been utilized in the past but are not widely used due to high operation and maintenance cost (Indraratna et al. 2010). In contrast, permeable reactive barriers (PRBs), a technique that has recently been considered for remediation of ASS, have a number of advantages such as no energy consumption, minimal operation and maintenance cost, and 
minimal disruption to the existing land (Indraratna et al. 2010). A PRB can consist of a trench filled with reactive material and covered again with top soil to allow existing land-use to continue (Golab et al. 2006). When this barrier intersects the flow path of contaminated groundwater, the reactive material will increase the $\mathrm{pH}$ of the groundwater to a level that causes $\mathrm{Fe}$ and $\mathrm{Al}$ to precipitate out of solution. The reactive material is also expected to have a permeability that allows the groundwater to pass freely through the barrier.

Although the application of PRBs to neutralize acidic groundwater from mining production has been extensively studied (Waybrant et al. 2002; Bulusu et al. 2005; Wang et al. 2006), little has been done to test the effectiveness of PRBs to solve ASS problems. A few studies have been performed to investigate the capacity of different reactive materials typically used in PRBs to neutralize acidity generated by ASS. Golab et al. (2009) performed several laboratory tests to assess the suitability of fly ash, fresh recycled concrete, slag, lime and breccia in neutralizing acidity, and noted that recycled concrete might be a preferable material for PRBs. Building upon these results, Regmi et al. (2011) carried out long-term laboratory experiments to study the neutralizing capacity and permeability of recycled concrete, while Indraratna et al. (2010) tested the ability of recycled concrete to neutralize the acidity of groundwater in a large-scale field experiment. The data from these studies indicated that recycled concrete could improve the $\mathrm{pH}$ of groundwater from acidic to mildly alkaline, and remove about $95 \% \mathrm{Fe}$ and $\mathrm{Al}$. However, it was also revealed that the armouring effect could occur in the PRB as a result of precipitation of $\mathrm{Fe}$ and $\mathrm{Al}$ on the surface of reactive material. This process can cause a decrease in the hydraulic conductivity of the reactive material as well as reduce the overall capacity of PRB to neutralize acidity. Thus, there is a need for further research to investigate the reactive properties of different material that can improve the long-term performance of PRBs (Gratchev et al. 2012). 
This study aims at assessing the feasibility of using fly ash, lime, and bentonite as reactive material for PRBs. The use of inexpensive and readily available fly ash has significant economic benefits for the PRB's production as it markedly reduces production costs. This paper seeks to evaluate the buffer capacity and permeability characteristics of various mixtures of fly ash with small amounts of lime and bentonite, and provide data necessary to determine whether such material can be suitable for a PRB. To evaluate the potential of such mixtures to effectively remediate acidic water for a long period of time, a series of buffer capacity tests and leaching experiments were carried out, in which changes in $\mathrm{pH}$ and electrical conductivity over time were monitored and recorded. Hydraulic conductivity tests on different mixtures permeated with acidic liquids were conducted to study changes in the permeability of soil over time. This paper presents and discusses the obtained results.

\section{Background}

Fly ash is a by-product produced in great amounts by coal-fired power generating stations around the world. Due to its low cost and availability, fly ash has been utilized in various civil engineering areas including cement and concrete applications, highway pavements, and backfills (Nhan et al. 1996). It has also been tested as a reactive material to remediate acid mine drainage (AMD) (Polat et al. 2002; Dermatas and Meng 2003). For example, Bulusu et al. (2005) reported a case study in which fly ash was utilized to reduce AMD at abandoned mines in the USA, while Wang et al. (2006) tested the feasibility of fly ash to control acid rock drainage (ARD) produced by mine tailings in Ontario.

It has been recognized that the capacity of fly ash to neutralize acid strongly depends on the content of calcium oxide $(\mathrm{CaO})$, a chemical compound that generates alkaline leachate in contact with water (Stouraiti et al. 2002). However, if the amount of calcium oxide is not sufficient or the long-term buffer capacity needs to be enhanced, a small amount of lime can 
be added to fly ash (Bulusu et al. 2005). When fly ash interacts with AMD, acid-base reaction neutralizes the acidity of liquid while the rising $\mathrm{pH}$ leads to stabilization of dissolved metals such as $\mathrm{Fe}$ and $\mathrm{Al}$ in the solution. In addition, secondary minerals, including gypsum, are formed from the reaction of calcium released from fly ash (or lime) and sulfate in the mining waste drainage. Wang et al. (2006) showed that the precipitation of metals and the formation of secondary minerals would result in "the void spaces between solid particles becoming clogged." This process can reduce the buffering capacity, porosity and permeability of fly ash, thus significantly undermining its long-term performance as a reactive material. However, a study performed by Yeheyis et al. (2010) indicated that addition of bentonite to fly ash can improve the long-term hydraulic conductivity of PRBs as the decrease in the hydraulic conductivity due to clogging can be offset by increases in pore space caused by reduction of the diffuse double layer thickness of bentonite particles. In addition, bentonite can also improve the capacity of fly ash mixtures to retard toxic metals such as Fe and Al. Kashir and Yanful (2001) carried out a series of experiments in which bentonite was permeated with AMD, and reported that only $20 \%$ of $\mathrm{Fe}$ in the AMD passed through the bentonite sample after as many as 12 pore volumes of flow. However, this study also revealed that bentonite did not have a sufficient, long-term buffering capacity, a property that can affect the capacity of bentonite - fly ash mixtures to neutralize acidity.

From the aforementioned studies it can be inferred that bentonite has the potential to improve the long-term performance of fly ash by reducing the negative effect of armouring and stabilizing toxic metals in the solution. However, the influence of bentonite on the buffer capacity and permeability of fly ash mixtures remains unclear and needs to be clarified.

\section{Experimental program}

\subsection{Material properties}


The materials used in this study were fly ash, lime and bentonite. Fly ash from Tarong power plant, Queensland, Australia was selected for this research. Although different types of fly ash are available in Queensland, all of them have low content of $\mathrm{CaO}$ ranging from 0 to 0.4\% (Zaeni et al. 2010). This indicates that the relatively low buffer capacity of these fly ashes needs to be enhanced by addition of lime. As the use of lime seems inevitable, it was decided to select this particular fly ash (with $0 \%$ of $\mathrm{CaO}$ ) as it was the most inexpensive material having the grain size distribution (Fig. 1) which was the most appropriate to produce mixtures with relatively higher values of hydraulic conductivity. According to Zaeni et al. (2010), the chemical composition of this fly ash includes: $\mathrm{SiO}_{2}(66.5 \%), \mathrm{Al}_{2} \mathrm{O}_{3}(28.9 \%)$, $\mathrm{Fe}_{2} \mathrm{O}_{3}(0.6 \%)$, and $\mathrm{TiO}_{2}(1.8 \%)$.

As fly ash is reactive material, there is a concern that leaching of heavy metals from fly ash can cause environmental problems. This prompted Wearing et al. (2004) to assess the potential for these metals to leach from the Tarong ash into the environment. Wearing et al. (2004) reported the results from the USEPA Toxicity Characteristics Leaching Procedure tests, indicating that "the trace elements are not in a form where they are easily leached from the matrix, and therefore do not present a significant environmental risk."

Commercially available hydrated lime $\left(\mathrm{Ca}(\mathrm{OH})_{2} \approx 90 \%\right)$ was used as a neutralising agent to improve the buffer capacity of the Tarong fly ash. Owing to its high calcium content, lime has been used in several studies to increase $\mathrm{pH}$ levels of groundwater (Ghosh and Subbarao 2006).

Commercially available sodium bentonite also known as "Bentonile" was kindly provided for this research by Sud-Chemie Australia Pty Ltd. The chemical composition of bentonite was as follows: $\mathrm{SiO}_{2}(67 \%), \mathrm{Al}_{2} \mathrm{O}_{3}(21.2 \%), \mathrm{Fe}_{2} \mathrm{O}_{3}(3.5 \%), \mathrm{Na}_{2} \mathrm{O}(3.3 \%), \mathrm{MgO}(2.5 \%), \mathrm{K}_{2} \mathrm{O}$ $(0.9 \%)$, and $\mathrm{CaO}(0.5 \%)$. The bentonite was in the form of powder with fines content $(<0.074$ $\mathrm{mm})$ of $98 \%$, and the clay fraction $(<0.002 \mathrm{~mm})$ of $92 \%$. 
Fly ash (FA) was mixed with lime (L) to form mixtures (called FAL) with various lime content such as $2.5 \%$ (FAL-2.5), 5.0\% (FAL-5), 7.5\% (FAL-7.5), and 10\% (FAL-10) by weight. To study the effect of bentonite on the long-term buffer capacity of the reactive material, $10 \%$ and $20 \%$ bentonite (by weight) were added to the FAL-5 and FAL-10 mixtures. FAL-10 and FAL-5 were selected as they represented the maximum and half of maximum values of lime, respectively.

\subsection{Test procedure}

\subsubsection{Buffer capacity tests}

Buffer capacity is the property of a soil that determines its resistance to $\mathrm{pH}$ changes. In this study, the buffer capacity of different material was determined experimentally by titrating each sample with increasing concentrations of sulfuric acid, following Yong et al. (1990), and Gratchev and Towhata (2009). Sulfuric acid (0.01 $\left.\mathrm{M} \mathrm{H}_{2} \mathrm{SO}_{4}\right)$ was first diluted with distilled water to certain concentrations, and then added to the soil at a ratio of $1: 10$, using $4 \mathrm{~g}$ of dry soil mixture and $40 \mathrm{~g}(\mathrm{ml})$ of acid solution. The $\mathrm{pH}$ of the soil solution was measured after the soil suspension sample was thoroughly shaken and allowed to stand for at least $24 \mathrm{~h}$.

\subsubsection{Leaching tests}

For leaching tests, the same amount of soil (4 g) and acidic liquid (40 ml) was utilized. Two acidic liquids with different acid content were prepared: 1) $10 \mathrm{ml} 0.01 \mathrm{M} \mathrm{H}_{2} \mathrm{SO}_{4}+30 \mathrm{ml}$ distilled water; and 2) $20 \mathrm{ml} 0.01 \mathrm{M} \mathrm{H}_{2} \mathrm{SO}_{4}+20 \mathrm{ml}$ distilled water. Similar to the buffer capacity tests, the soil specimen was first mixed with the acidic liquid and allowed to rest for 24 hours. Then, the effluent liquid was removed from the container, and the liquid's $\mathrm{pH}$ and electrical conductivity were measured and recorded. After the measurement, the container was re-filled with the acidic liquid to maintain the desired $\mathrm{pH}$ value of the influent throughout the 
whole test. This process was repeated until the soil samples lost most of their buffer capacity; that is, the $\mathrm{pH}$ values of influent and effluent liquids became very similar.

\subsubsection{Compaction tests}

A series of standard Proctor compaction tests were performed on mixtures of fly ash with lime and bentonite. The tests were conducted in accord with the Australian Standard (AS 1289 5.1.1-2003), in which the sample compaction was achieved in three equal layers, with each layer being subjected to 25 blows. The results of these tests, including the optimum moisture content, were used to prepare soil specimens for hydraulic conductivity tests.

\subsubsection{Hydraulic conductivity tests}

A series of hydraulic conductivity tests were conducted to study the influence of $\mathrm{pH}$ on the coefficient of permeability of FAL-10 with different amounts of bentonite. In each test, the specimen was first compacted in the mould at the optimum moisture content, and then subjected to a constant hydraulic flow of distilled water to obtain the reference hydraulic conductivity. It is noted that the optimum moisture content for each mixture is presented in Fig. 6 and discussed in the relevant section 4.3, while the reference hydraulic conductivity is given in Fig. 7b and discussed in the section 4.4.

After the specimen was brought to equilibrium using 3L of water permeation, acidic solution with $\mathrm{pH}=3.0$ was introduced into the specimen. The volume of permeated liquid, $\mathrm{pH}$ and electrical conductivity of the effluent liquid were monitored throughout the test. The coefficient of permeability was determined after every $1.0-1.5 \mathrm{~L}$ of permeation, according to the "Falling head" method (AS 1289 6.7.2-2001).

\section{Test results}




\subsection{Buffer capacity tests}

The titration curves of $\mathrm{pH}$ against sulfuric acid input for the three soil suspensions are shown in Fig. 2. Also included in the figure is the titration curve of a blank (a solution in the absence of soil). The plot shows that the buffer capacity of fly ash sample is relatively poor. The $\mathrm{pH}$ of effluent liquid gradually declined from a value of 4.9 (distilled water) to 3.6 as the acid input increased from 0 to $90 \mathrm{cmol} \mathrm{H}_{2} \mathrm{SO}_{4} \mathrm{~kg}^{-1}$.

In contrast, the lime exhibits a high buffer capacity. The specimen with distilled water returned an effluent $\mathrm{pH}$ value of 12.1 , and each sample after that showed only a fractural decrease in $\mathrm{pH}$ with an increasing quantity of acid. The buffer capacity of bentonite is also high, which can be attributed to a high cation exchange capacity of the clay (Gratchev and Towhata 2010).

\subsection{Leaching tests}

4.2.1 Leaching tests on mixtures of fly ash and lime

A series of leaching tests were conducted on mixtures of fly ash with different lime content: $2.5 \%, 5 \%, 7.5 \%$, and $10 \%$ by weight. The data obtained from these tests are presented in Fig. 3 in terms of the number of leaching rounds against the $\mathrm{pH}$ of effluent liquid. Different acidic liquids were utilized in these experiments: $10 \mathrm{ml} 0.01 \mathrm{M} \mathrm{H}_{2} \mathrm{SO}_{4}+30$ $\mathrm{ml}$ distilled water (Fig. 3a), and $20 \mathrm{ml} 0.01 \mathrm{M} \mathrm{H}_{2} \mathrm{SO}_{4}+20 \mathrm{ml}$ distilled water (Fig. 3c). It is evident from these figures that the specimens with higher lime content exhibited a greater resistance to changes in $\mathrm{pH}$.

As the total dissolved solids leached from the specimens can be represented by the electrical conductivity of the effluent (Wang et al. 2006), it is important to study this variable over time to better understand the processes that affect the buffer capacity of soil during leaching. For this reason, the variations of electrical conductivity of the effluent liquid with an 
increasing number of leaching rounds for both concentrations of sulfuric acid are presented in Figs. $3 \mathrm{~b}$ and $3 \mathrm{~d}$, respectively. For all specimens, a decrease in the electrical conductivity was observed in the first few rounds of leaching, with the sharpest decline being associated with the specimens of lower lime content. A decrease of electrical conductivity was also reported by Wang et al. (2006), and Perez-Lopes et al. (2007) who noted that high values of electrical conductivity at the beginning of each leaching test were due to the presence of large concentrations of dissolved solids in the effluent. In the present study, the dissolution of calcium from the lime likely increased the electrical conductivity as well as the alkalinity of the effluent. However, as the leaching rounds continued, the dissolved solids in the effluent decreased due to precipitation and possible formation of secondary minerals, as indicated by the decrease in the electrical conductivity. These processes appear to reduce the mixture capacity to neutralize acid, leading to a decrease in the $\mathrm{pH}$ of the effluent liquid as shown in Figs. 3a,c. As the buffer capacity of the mixtures greatly depend on the lime content, it is logical to assume that a more rapid decrease in the electrical conductivity and $\mathrm{pH}$ of the effluent liquid due to the leaching should occur in the mixtures having lower amounts of lime (Ghosh and Subbarao 2006).

\subsubsection{Leaching tests on mixtures of fly ash, lime and bentonite}

Results of leaching tests on the fly ash and lime mixtures with bentonite are presented in Fig. 4 for the acidic liquid of $10 \mathrm{ml} 0.01 \mathrm{M} \mathrm{H}_{2} \mathrm{SO}_{4}+30 \mathrm{ml}$ distilled water, and Fig. 5, for the acidic liquid of $20 \mathrm{ml} 0.01 \mathrm{M} \mathrm{H}_{2} \mathrm{SO}_{4}+20 \mathrm{ml}$ distilled water. The behavior of two mixtures, namely FAL-5 and FAL-10, were studied in relation to different bentonite content. As can be seen in Fig. 4a, the behavior of FAL-5 with and without bentonite when subjected to the same number of leaching rounds seems to be very similar. It is evident from this figure that addition of bentonite to FAL-5 does not affect the long-term buffer capacity of the mixtures. However, 
when the mixture of FAL-10 used (Fig. 4c), the effect of bentonite became more pronounced as the buffer capacity of FAL-10 with $10 \%$ and $20 \%$ bentonite decreased. For example, after 10 rounds of leaching, the $\mathrm{pH}$ of effluent liquid obtained for the specimens of FAL-10 with $10 \%$ and $20 \%$ bentonite was about 8 while the pH of FAL-10 without bentonite was 9.2.

The same relationship was observed for a greater acid content (Fig. 5). Comparisons made between the FAL-5 (Fig. 5a) and FAL-10 (Fig. 5c) mixtures indicate that the effect of bentonite is more pronounced when the higher lime content of $10 \%$ is utilized. Thus, it may be concluded that, compared to FAL-5, addition of bentonite to the FAL-10 mixture seems to decrease the overall capacity of this material to neutralize the acidic solution. Changes in the electrical conductivity and its relationship with $\mathrm{pH}$ observed in these experiments are consistent with the data discussed in the previous section (Fig. 3).

\subsection{Compaction tests}

Compaction characteristics of fly ash and lime mixtures with different amounts of bentonite are shown in Fig. 6, in which dry densities of compacted samples are plotted against the corresponding moisture content. It is clear from this figure that the maximum dry density of the studied mixtures increases with the increasing amount of bentonite. The optimum moisture content obtained for all samples seems to be in a narrow range of 32-35\%. It is noted that the obtained results are in agreement with the data presented by Mollamahmutoglu and Yilmaz (2001), who studied the effect of bentonite on the compaction characteristics of fly ash.

\subsection{Hydraulic conductivity tests on fly ash with lime and bentonite}

The results of hydraulic conductivity tests on mixtures of fly ash and lime (FAL-10) with $10 \%$ and $20 \%$ bentonite are given in Fig. 7. All specimens were first permeated with $3 \mathrm{~L}$ of 
distilled water, followed by introduction of acidic liquid with $\mathrm{pH}=3.0$. The experiments were performed for a total of approximately $55 \mathrm{~L}$ of water and acidic liquid permeation.

Figure 7a shows $\mathrm{pH}$ measurements as a function of effluent volume. It is interesting to note that all samples exhibited no change in $\mathrm{pH}$ during the first $10 \mathrm{~L}$ of water and acidic fluid permeation. However, during the next $10 \mathrm{~L}$ of permeation, the effluent $\mathrm{pH}$ of FAL-10 remained almost the same (about 12) while for the mixtures of FAL-10 with bentonite, the $\mathrm{pH}$ values decreased. It is also evident from this figure that the effluent $\mathrm{pH}$ of FAL-10 with $20 \%$ bentonite decreased more rapidly compared to that of FAL-10 with $10 \%$ bentonite. This trend continued until the end of the tests, with the FAL-10 showing the highest buffer capacity while the FAL-10 with $20 \%$ bentonite demonstrated the lowest. These results are in agreement with the data from the leaching tests (Figs. $4 \mathrm{~b}$ and $5 \mathrm{~b}$ ), providing more support for the hypothesis that addition of bentonite may decrease the buffer capacity of lime - fly ash mixtures.

The results of "Falling head" tests on the mixtures of FAL-10 and FAL-10 with different contents of bentonite are shown in Fig. $7 \mathrm{~b}$. As can be seen in this figure, the average coefficient of permeability of FAL-10 was initially about $0.017 \mathrm{~mm} / \mathrm{s}$ within the first $3 \mathrm{~L}$ of water permeation. After the acidic liquid was introduced, the hydraulic conductivity first slightly increased to $0.02 \mathrm{~mm} / \mathrm{s}$ after about $17 \mathrm{~L}$ and then increased sharply to almost 0.08 $\mathrm{mm} / \mathrm{s}$. It is interesting to note that the same trend was also observed for FAL-10 with $10 \%$ and $20 \%$ bentonite (Fig. $7 b)$.

Changes in the hydraulic conductivity of fly ash mixtures permeated with AMD were studied by Shang et al. (2006), and Wang et al. (2006) who noted that due to the precipitation of metals from AMD and formation of secondary minerals, the voids between solid particles would be clogged, resulting in a decrease of the hydraulic conductivity. However, in this work, only acidic liquids (that is, diluted sulfuric acid) were used, and thus the process of 
clogging is expected to have a much smaller effect compared to the aforementioned studies. In fact, the data given in Fig. $7 \mathrm{~b}$ indicate that the hydraulic conductivity of fly ash mixtures might increase when permeated with acidic liquids. A similar finding was presented by Mollamahmutoglu and Yilmaz (2001) who permeated bentonite-fly ash mixtures with acidic solutions of $\mathrm{HCl}$ for over 150 days. Nhan et al. (1996) also reported an increase in the hydraulic conductivity of bentonite-fly ash mixtures permeated with a synthetic leachate with a low pH. Shang et al. (2006) suggested that an increase in the hydraulic conductivity of fly ash can occur due to the increase of void space of soil samples when the dissolved solids generated by the acidic pore fluid are leached out. Wang et al. (2006) also noted that some fine particles can be flushed out of fly ash during permeation, increasing the void space and thus the hydraulic conductivity of samples.

For the mixtures of FAL-10 with $10 \%$ and $20 \%$ bentonite, an increase in the hydraulic conductivity was also observed during the acidic permeation. This change in the permeability can be attributed to the reduction of the diffuse double layer of bentonite particles caused by high concentration of ions in the pore fluid (Van Olphen 1977; Nayak et al. 2007), and the formation of large clay aggregates with more open, flocculated clay microfabric (Gratchev et al. 2007). Such flocculated microfabrics of bentonite will provide greater void space for water to flow increasing the hydraulic conductivity (D’Appolonia 1980; Kashir and Yanful 2001). It is interesting to note that an increase in the hydraulic conductivity of FAL-10 with $20 \%$ bentonite after $20 \mathrm{~L}$ of acidic permeation was slightly greater than the one observed for FAL10 with $10 \%$ bentonite. It is hypothesised that despite the increase in the bentonite content, the formation of more open flocculated structures would occur at a larger scale in FAL-10 with $20 \%$ bentonite when permeated with acidic liquids, which would increase the hydraulic conductivity of this mixture. Similar behavior was reported by Yeheyis et al. (2010) who permeated bentonite-fly ash mixtures with AMD. 


\section{Conclusion}

This paper presents the results of an experimental study in which the long-term buffer capacity of fly ash mixtures with different amounts of lime and bentonite was assessed. Based on the obtained results, the following conclusions can be drawn:

- An increase in lime content results in a greater long-term buffer capacity of the Tarong fly ash;

- Addition of bentonite to lime - fly ash mixtures may decrease the long-term capacity of such mixtures to neutralize acidity;

- Addition of bentonite to lime - fly ash mixtures may increase the maximum dry density of the mixtures;

- When permeated with acidic liquids, the hydraulic conductivity of fly ash mixtures with lime and bentonite can increase.

It is noted that this study aims at assessing the capacity of fly ash, lime, and bentonite to neutralize acidity. Although promising results were obtained, the performance of these mixtures with real leachates that contain metal ions such as $\mathrm{Fe}$ and $\mathrm{Al}$ can be different and require further investigation. Nevertheless, the data presented here can be utilized for selection of reactive material for testing in field conditions in future studies.

\section{ACKNOWLEDGEMENTS}

The authors acknowledge the help of Mrs. Angus Brennan and Alistair Inoue with laboratory testing. The Tarong fly ash and bentonite were kindly provided for this study by Cement Australia and Sud-Chemie Australia Pty Ltd, respectively. This research was supported by the NRG grant from Griffith University, Australia. 


\section{REFERENCES}

Australian Standard AS 1289 5.1.1-2003 (2003) Soil compaction and density tests Determination of the dry density/moisture content ratio of a soil using standard compactive effort

Australian Standard AS 1289 6.7.2-2001 (2001) Method of testing soils for engineering purposes: Method 6.7.2 Soil strength and consolidation tests - Determination of permeability of a soil -Falling head method for remoulded specimen

Bulusu S, Aydilek AH, Petzrick P, Guynn R (2005) Remediation of abandoned mines using coal combustion by-products. Journal of Geotechnical and Geoenvironmental Engineering ASCE 131 (8): 958-969

D'Appolonia D (1980) Soil-bentonite slurry trench cutoffs. Journal of Geotechnical and Geoenvironmental Engineering ASCE 106 (4): 399-417

Dermatas D, Meng XG (2003) Utilization of fly ash for stabilization/solidification of heavy metal contaminated soils. Engineering Geology 70 (3-4): 377-394

Ghosh A. Subbarao C (2006) Leaching of Lime from Fly Ash Stabilised with Lime and Gypsum. Journal of Materials in Civil Engineering 18: 106-115

Golab AN, Peterson MA, Indraratna B (2006) Selection of Potential Reactive Materials for a Permeable Reactive Barrier for Remediating Acid Groundwater in Acid Sulfate Soil Terrains. Q J Eng Geol Hydrogeol 39: 209-223

Golab AN, Peterson MA. Indraratna B (2009) Selection of Permeable Reactive Barrier Materials for Treating Acidic Groundwater in Acid Sulfate Soil Terrains Based on Laboratory Column Tests. Journal of Environmental Earth Science 59: 241-254

Gratchev I, Sassa K, Osipov V, Fukuoka H, Wang G (2007) Undrained cyclic behavior of bentonite-sand mixtures and factors affecting it. Geotechnical and Geological Engineering 25: $349-367$ 
Gratchev I, Shokouhi A, Inoue A, Brennan A (2012) Feasibility of using bentonite lime and fly ash in permeable reactive barriers for acid sulfate soils. In the $11^{\text {th }}$ Australia New Zealand Conference on Geomechanics (ANZ 2012) Melbourne : 7-12

Gratchev I, Towhata I (2009) Effects of Acidic Contamination on the Geotechnical Properties of Marine Soils in Japan. Proc ISOPE-2009 Osaka: 19th International Offshore (Ocean) and Polar Engineering Conference: 151-155

Gratchev I, Towhata I (2010) Compressibility of natural soils subjected to long-term acidic contamination. Environmental Earth Sciences 64 (1): 193-200

Gratchev I. Towhata I (2013) Stress-strain characteristics of two natural soils subjected to long-term acidic contamination. Soils and Foundations 53 (3): 469-476 http://dx.doi.org/10.1016/j.sandf.2013.04.008

Indraratna B, Glamore WC, Tularam GA (2002) The Effects of Tidal Buffering on Acid Sulfate Soil Environments in Coastal Areas of New South Wales. Journal of Geotechnical and Geological Engineering 20: 181-199

Indraratna B, Regmi G, Nghiem LD, Golab AN (2010) Performance of a PRB for the Remediation of Acidic Groundwater in Acid Sulfate Soil Terrain. Journal of Geotechnical and Geoenvironmental Engineering ASCE 136 (7): 897-906

Kashir M, Yanful EK (2001) Hydraulic Conductivity of Bentonite Permeated with Acid Mine Drainage. Journal Can Geotech 38: 1034-1048

Mollamahmutoglu M, Yilmaz Y (2001) Potential use of fly ash and bentonite mixture as liner or cover as waste disposal areas. Environmental Geology 40: 1316-1324

Nataatmadja A, Morgan P (1999) Characterisation of Queensland's fly ash. In Proc $8^{\text {th }}$ Australia New Zealand conference on geomechanics: 769-774

Nayak S, Sunil BM, Shrihari S (2007) Hydraulic and compaction characteristics of leachatecontaminated lateritic soil. Engineering Geology 94: 137-144 
Nhan CT, Graydon JW, Kirk DW (1996) Utilizing coal fly ash as a landfill barrier material. Waste Management 16 (7): 587-595

Olphen H (1991) An introduction to clay colloid chemistry. Krieger Publishing Company

Polat M, Guler E, Akar G, Morgodan H, Ipekoglu U, Cohen H (2002) Meutralization of acid mine drainage by Turkish lignitic fly ashes: role of organic additives in the fixation of toxic elements. Journal of Chemical Technology and Biotechnology 77(3): 372-376

Perez-Lopes R, Nieto JM, Almodovar GR (2007) Utilazation of fly ash to improve the quality of the acid mine drainage generated by oxidation of a sulphide-rich mining waste: column experiments. Chemosphere 67: 1637-1646

Regmi G, Indrarata B, Nghiem LD, Golab A, Guru Prasad B (2011) Treatment of Acidic Groundwater in Acid Sulfate Soil: Column Experiments. Journal of Environmental Engineering 137(6): 433-443

Stouraiti C, Xenidis A, Paspaliaris I (2002) Reduction of Pb Zn and Cd availability from tailings and contaminated soils by the application of lignite fly ash. Water, Air, and Soil Pollution 137: 247-265

Van Olphen H (1977) Introduction to colloid chemistry. Wiley New York

Wang HL, Shang JQ, Kovac V, Ho KS (2006) Utilization of Atikokan coal fly ash in acid rock drainage control from Musselwhite Mine tailings. Canadian Geotechnical Journal 43 (3): $229-243$

Waybrant KR, Ptacek CJ, Blowes DW (2002) Treatment of mine drainage using permeable reactive barriers: column experiments. Environ Sci Technol 36: 1349-1356

White I, Melville MD, Wilson BP, Sammut J (1997) Reducing acidic discharges from coastal wetlandsin eastern Australia. Wetlands Ecol Manage 5(1): 55-72

Yeheyis MB, Shang JQ, Yanful EK (2010) Feasibility of Using Coal Fly Ash for Mine Waste Containment. Journal of Environmental Engineering 136(7): 682-690 
Yong RN, Warkentin BP, Phadungchewit Y, Galvez R (1990) Buffer Capacity and lead Retention in Some Clay Materials. Journal of Water, Air, and Soil Pollution 53: 53-67

Zaeni A, Bandyopadhyay S, Yu A, Rider J, Sorrell C, Dain S, Blackburn D. White C (2010) Colour control in fly ash as a combined function of particle size and chemical composition. Fuel 89: 399-404 
Figure captions.

Figure 1. Grain size distribution of Tarong fly ash.

Figure 2. Results of buffer capacity tests.

Figure 3. Results of leaching tests on mixtures of fly ash with different content of lime using acidic liquids of $10 \mathrm{ml} 0.01 \mathrm{M} \mathrm{H}_{2} \mathrm{SO}_{4}+30 \mathrm{ml}$ distilled water (a,b), and $20 \mathrm{ml} 0.01 \mathrm{M} \mathrm{H}_{2} \mathrm{SO}_{4}$ $+20 \mathrm{ml}$ distilled water $(\mathrm{c}, \mathrm{d})$.

Figure 4. Results of leaching tests on mixtures of fly ash with lime and bentonite permeated with acidic liquid of $10 \mathrm{ml} 0.01 \mathrm{M} \mathrm{H}_{2} \mathrm{SO}_{4}+30 \mathrm{ml}$ distilled water: FAL-5 (a,b), and FAL-10 $(\mathrm{c}, \mathrm{d})$.

Figure 5. Results of leaching tests on mixtures of fly ash with lime and bentonite permeated with acidic liquid of $20 \mathrm{ml} 0.01 \mathrm{M} \mathrm{H}_{2} \mathrm{SO}_{4}+20 \mathrm{ml}$ distilled water: FAL-5 (a,b), and FAL-10 $(\mathrm{c}, \mathrm{d})$.

Figure 6. Results of standard Proctor compaction tests.

Figure 7. Results of hydraulic conductivity tests using FAL-10 with different bentonite content plotted as: (a) $\mathrm{pH}$ of the effluent liquid against volume of permeation, and (b) the coefficient of permeability against volume of permeation. 